Liliana Adiers Lohmann

Colégio Militar do Rio de Ja neiro

Sebastiã o J osué Votre

Universidade Gama Filho

\title{
A inserção acadêmica e esportiva da primeira tuma feminina no Colégio Militar do Rio de Janeiro
}

\begin{abstract}
Resumo: Os objetivos deste traba lho sã o contextualizar o a mbiente em que se deu a inserção da primeira turma feminina no Colégio Militar do Rio de Ja neiro, em 1989, bem como identificar e ana lisar as representaç ões femininas e masculinas sobre a inserção aca dêmic a e esportiva dessa primeira turma. A metodologia, qualita tiva e etnográfica, fundamenta-se na teoria das representações sociais. ${ }^{1}$ Os dados provêm da observação participante e de seis entrevistas individuais não-diretivas de "elite": três ex-alunas e três homens. Analisam-se também reportagens de jornais e revistas, de 1989 a 1996. Constata-se que cuidado e diferença são constantes no disc urso dos dois grupos de informantes. Conclui-se que o incentivo ao esporte, proposto pelo comandante do Colégio e liderado pela professora de Educação Física coautora deste trabalho, influenciou e consolidou o espaço para a participação e integração feminina no Colégio e para o seu êxito acadêmico e esportivo.
\end{abstract}

Palavras-chave: mulheres; gênero; educa ção físic a; representações socia is; Colégio Militar.

Copyright 2006 by Revista Estud os Feministas.

${ }^{1}$ Serge MOSC OVICI, 1978 e 2003; e Wolfgang WAGNER, 2002.

2 Mic hel THIO LENT, 1987.

${ }^{3}$ Cynthia A. SART, 2004, p. 35-50.

${ }^{4}$ Pierre BOURDIEU, 1999.

\section{Introdução}

A partir da década de 1970 sinalizaram-se a vanços da participação das mulheres em novos campos da atividade humana no Brasil,, ${ }^{3}$ sobretudo em setores que, nos termos de Pierre Bo urd ieu, ${ }^{4}$ sã o extensã o da família. Em 1979 caía o Decreto-Lei no 3.199, de 1941, que proibia qualquer esporte considerado incompatível com as "corretas e natura is condições e funções femininas". Em 1982 caía ta mbém a Sétima Deliberação do Conselho Nacional de Esportes, de 1965, que no Governo de Castelo Branco regulamentava a referida lei e impedia às mulheres a prática de futebol, futsal, futebol de a reia, pólo a quá tic 0 , ha lterofilismo e beisebol. 
${ }^{5}$ SARTI, 2004

6 RELATÓ RIO GERAL SOBRE A MULHER NA SOCIEDADE BRASILEIRA, 1995.

${ }^{7}$ Guacira LOURO, 2002, p. 16

8 LOURO, 2002, p. 19.

${ }^{9}$ Ra quel SOIHET, 1997.

${ }^{10} \mathrm{As}$ mulheres bra sileira s estã o isentas do serviço militar, na forma prevista pela Constituição, porém Ines é permitida a prestação de serviç o militar voluntá rio, segundo critérios de conveniência e oportunidade de cada Ama.

${ }^{11}$ Boletim Intemo n. 204, de 4 de novembro de 1988.

12 Inscreveram-se 7.099 candidatos, dos qua is 2.604 eram meninas e 4.495 , meninos.

${ }^{13}$ MANC HEIE ESPEC IAL, 1995, p 37.
Esses avanços e conquista s ampliaram-se durante a transição democrática da década de $1980 .{ }^{5}$ Com efeito, em 1983 nasciam os Conselhos Esta dua is da Condição Feminina e dos Direitos da Mulher. Em 1985, registravase a criação do Conselho Nacional dos Direitos da Mulher. ${ }^{6}$

Foi nesse contexto de "efervescência social e política, de contestação e de transformação, que o movimento feminista contemporâneo no Brasil ressurgiu". ${ }^{7}$ As mulheres passaram a ter visibilidade crescente em diferentes segmentos da sociedade, e suas lembranças e "histórias de vida, fontes ic onográficas, reg istros pessoa is e diários" passaram a ser utiliza dos por pesquisadores/as, considerando que tais registros "tinham origem numa trajetória histórica específica, que construiu o lugar social das mulheres e que o estudo de tais questões tinha pretensões de mudanças". ${ }^{8}$ Passava-se a compreendernão mais uma mulher genérica, ${ }^{9}$ mas múltiplas e complexas identida des femininas, contextua Imente estabelecidas.

A inclusão de mulheres nos Colégios Militares do Exército bra sileiro, no final dos anos 1980, articulou-se com o processo de democratização da sociedade brasileira e com a expansão da busca de igualda de de oportunida des entre os sexos na educação militar e na própria carreira militar. ${ }^{10}$ Em 1987, a Portaria Ministerial 810/87

decidiu otimizar o ensino preparatório e assistencial do Exérc ito. Assim, a nova orientação determina: Adotarum regime de ensino nos primeiro e segundo graus semelhante à quele desenvolvido nos estabelecimentos de ensino civis congêneres, acrescido da educação paramilitar. [...] Transformar em misto o corpo discente, destinando $30 \%$ das vagas para o sexo feminino, sem diminuir o efetivo atual de alunos. ${ }^{11}$

O concurso público realizou-se no início de dezembro de 1988. Em 1989 elas entravam nos cinco Colég ios Milita res entã o a tivos: Rio de J a neiro, Bra sília, Porto Alegre, Fortaleza e Manaus. No caso do Rio, para as primeiras 120 vagas oferecidas, as meninas concorreram a 30 , enquanto 90 foram reservadas aos rapazes. ${ }^{12}$ Procedeu-se a uma pequena reformulação da proposta c urric ular, na parte das a tivida desfísic o-desportivas. A pa rte estrutural também sofreu adaptações, com reforma de banheiros e vestiários.

Segundo a revista Manchete, 13 "Um século depois de sua fundação, no início do a no letivo, [...] meninas a travessam os portões do centenário Colégio Militar do Rio de Janeiro, para cumprir e obedecer às mesmas nomas disciplinares e a o mesmo currículo dos meninos". Ainda 
${ }^{14}$ J ORNALDO BRASIL, 1993, p. 5457.

15 WELLR, 2005, p. 103-105.
${ }^{16}$ A co-autora trabalhou com as alunas de 1993 a 1996.

${ }_{17}^{17}$ THIOLENT, 1987.

18 BOURDIEU, 1973; MIC HELAT, 1973.

${ }^{19}$ As três ex-a lunas, filhas de civis, são: Clarice Echardt de Oliveira Chaves, aluna graduada em grande parte da sua trajetória escolar, expoente do esporte, homenageada como destaque esportivo do Colégio em 1994 e 1995; Flá via de Holanda Sc hmidt, que seguiu a carreira militar, fazendo parte da primeira turma feminina na Academia da Força Aérea e destacou-se nas equipes de Atletismo e Judô do Colégio; Márcia Cristina de Freitas Couto, aluna graduada, destaque nas avaliações intelectuais e físicas, primeira comandante feminina do Esquadrão de Cavalaria. segund o a revista, "A dec isã o de cria r a s turma s mista s vem no exa to momento em que o Exército atua, decisivamente junto às comunidades". Os tópicos abordados ilustram o quã o pequena parecia a refomula ção c uric ulare o qua nto se va loriza va a decisão de abriro Colég io à smeninas. Cinco a nos depois, o assunto foi reporta gem na Revista de Domingo do Jornal do Brasil, ${ }^{14}$ que reverberava os movimentos feministas da época, com o sugestivo título: "Outra guerra dos sexos". Na reportagem, a juventude feminina era apresentada como agentiva, consciente de sua competência e responsável: "As a lunas da primeira tuma [...] sabiam [...] que ao ingressarem ali estariam invadindo um território até então dominado pelos homens, com a missão de provar que não Ihes faltava competência para estuda rem sa las de tra dição centená ria". A imagem bélic a da invasão de território ilustrava o espírito dos movimentos da socieda de c ivil da época, que a tribuía m vonta de política e espínto de luta a pré-adolescentes, que - aparentemente - não estariam envolvidas com a luta das mulheres ma is velhas.

Vivian Weller ${ }^{15}$ nosalerta sobre a ausência de estudos sobre jovens adolescentes do sexo feminino e sobre os preconceitos em to mo de algumasculturas juvenis femininas que, "qua ndo vistas de forma superficial e estereotipada, parecem não demonstrar uma atitude de protesto diante das desigualdades de gênero ou de resistência", mas que se faz necessária a "desnaturalização da situação". A a ná lise da inserção da juventude feminina no meio militar, no processo de reconfiguração do lugarsocial das mulheres e de sua visibilização, comprova a pertinência das colocações da autora.

A pesquisa, com suporte da observação participante, ${ }^{16}$ consiste na a nálise de seis entrevistas ind ividua is não-diretivas, de "elite", concedidas por a lunas e professores da primeira turma, e de documentos escritos na imprensa local. O modo de construir e interpretar a a mostra segue Michel Thiollent, ${ }^{17}$ com suporte em Pierre Bourdieu e Guy Michelat. ${ }^{18}$ Selecionamos as três ex-alunas mais brilhantes, após examinarmos o perfil acadêmico e esportivo das participantes da primeira turma, a partir de consulta aos registros do "arquivo morto" do Colégio e de reportagens da imprensa escrita. As três se revela ram líderes acadêmicas e esportivas dessa turma. Informantes prototípicas, num certo sentido elas incorporam as representações da turma. ${ }^{19}$ Também os docentes são informantes de "elite". O professor Edvan coordenava a seção de educação física. O coronel Arume era comandante da quinta série e o coronel Mosqueira comandava a arma de Cavalaria. Portanto, a qualificação 
${ }^{20}$ MOSC OVICI, 2003, p. 34-37.

${ }^{21} \mathrm{MOSCOVICl}, 2003$, p. 40.
22 No caso deste estudo, as memórias são rela tadasa pósum lapso de 10 anos.

23 MOSC OVICI, 1978; Seba stião VOTRE e Ca rlos FIG UEIREDO, 2001.

${ }^{24}$ Para RORTY, 1994, somos signos lingüístic OS.

${ }^{25}$ VOTRE e FIGUEIREDO, 2001.
26 Laurence BARDIN, 1977; Fabiano DEVIDE, 2005; Seba stiã o VOTRE, 2004.

${ }^{27}$ Antônio FIGUEIREDO e Arivaldo Silveira FONTES, 1958.

${ }^{28}$ Ca rol GILLIGAN, 1990, p. 115.

${ }^{29}$ Fabiano DEVIDE, 2003 e 2005; Ludmila MOURÃO, 1988 e 2003; Ludmila MOURÃO e Euza GOMES, 2004 e 2005; Ludmila MOURÃO e Márcia MOREL, 2005; Gabriela SOUZA DE OLVEIRA, 2003; Gabriela SOUZA DE OUVEIRA e Juliana Santos COSTA, 2005; Lúcia REIS 1997; Ela ine ROMERO, 1990; Antônio SIMÕESe J orge KNIJ NIK, 2004; VOTRE e MOURÃO, 2003; Silvana GOELNER, 2001, 2003, 2005. das alunas e dos professores confere confiabilidade a suas fa las. A essa s pesso as solic itamos que nos conced essem uma entrevista nã o-diretiva, a partirda seguinte questã o: - c omo avaliam e representam a experiência vivida no Colégio Militar, no contexto de ingresso da primeira turma feminina, nos planos acadêmico e esportivo?

Postula mos que os sa beres e dizeres releva ntes sobre a inserção acadêmica e esportiva das alunas no universo militar masculino se manifestam como representações so c ia is ${ }^{20}$ compartilha das por essas pessoas, que intera gem de forma sistemática, têm interesses específic os nos tópic os em que interagem, lidam diariamente com os mesmos referenciais, compartilham normas e buscam altemativas de conviver com essas normas ou de contorná-las. Moscovici²1 afirma que "todas as interações humanas, surja m entre duas pessoas ou entre dois grupos, pressupõem representações; [...] quando nós encontramos pessoas ou coisa s e nos familia riza mos com elas, ta is representações estão presentes, são produtos de nossas ações e comunicações". Segundo o autor, operamos com modos privilegiados de lidarmos com a memória, construirmos conhecimento e orientarmos nossas práticas. ${ }^{22} \mathrm{~A}$ verba lização dos recursos de objetiva ção e ancoragem ${ }^{23}$ da qualific ação, descrição e a valiação de pessoas, processos, objetos e espaços do Colégio Militar é o foco da a ná lise. A linguagem é a ssumida nos termos de Ric hard Rorty ${ }^{24}$ como criadora de representações, pela gramatica liza ção das formas que ma is se utilizam. ${ }^{25}$

Pa ra identific a rasc a teg orias a na lític as que a ric ula m as representações sobre o ingresso das alunas na Escola Militar, seguindo a orientação de Thiollent, retardamos a categorização e, a pós nos impregnarmos das vozes dos grupos de informantes, vimos aflorarem cuidado e diferença. ${ }^{26}$ Procuramos compreender e avaliar as condições de produção do discurso oral através da captação de informações que emergem das entrevistas femininas e masculinas e do material impresso.

Da análise resultam leitura e interpretação positiva do ambiente pedagógico do Colégio Militar, concebido por homens e para homens, ${ }^{27}$ segundo princípios explícitos de hiera rquia, disciplina, responsabilidade e ética masculina do dever, do direito e da justiça, que acolhe mulheres identific adas com a ética do cuidado, e que privilegiam as noções de responsabilidade e solidariedade. ${ }^{28}$

Esperamos contribuir para a emerg ência de histórias recentes de inserção da juventude feminina em novos fronts masculinos, a exemplo do que se vem verificando nos mercados de trabalho e lazer, ou de diferentes segmentos no esp orte de rendimento ${ }^{29}$, e trazer à tona suas dific uld ades, 
${ }^{30}$ BO URDIEU, 1999.

${ }^{31}$ WAGNER, 2002, p. 166.
32 Incluímos nome do informante quando tal nos pareceroportuno.

${ }^{33}$ SARTI, 2004.

35 Vide Neise Gaudêncio ABREU, 1990; Elaine ROMERO, 1990; Maria do Carmo Saraiva KUNZ, 1993; Eustáquia Salvadora SOUSA, 1994; Greice Kelly OLIVEIRA, 1996; José Luiz FERREIRA, 1996; Helena ALTMANN, 1998; Eliete do Carmo Garcia VERBENA, 2001; Cátia Pereira DUARTE, 2003; Sissi Aparecida Martins PEREIRA, 2004.

êxitos e oportunidades nessas áreas de tensão e conflito, espaços de reserva da dominação masculina. ${ }^{30} \mathrm{~A}$ análise das representações e práticas dessas a toras disc entes e dos professores, bem como dos registros da imprensa local do Rio de Janeiro, mostram o que Wagner ${ }^{31}$ prevê em seu estudo: "As representações de um único e mesmo projeto social estã o presentes em vá rios esta dos de elaboração em diferentes subgrupos e incluem aspec tos diferenciados do objeto, que variam na relevância que têm para cada subgrupo".

\section{Interação inicial das a lunas com o Colégio}

No discurso docente sobre o contexto do ingresso das primeiras alunas nos bancos escolares militares, despontam considerações sobre a abertura do ensino para as mulheres nas Forças Armadas em geral, e no Exército em particular. Registra-se que a entrada de alunas no Colégio resultou da opção do Exército em atualizar-se, equiparando-se à Marinha e à Aeronáutica quanto à partic ipação feminina nos seus quadros: "só depois, como a Marinha e Aeronáutica começou a introduzir o quadro feminino, o Exército começou a pensar". ${ }^{32}$ Por outro lado, a efervescência do movimento feminista, que buscava nova s conquista sinstituc iona is na época, ${ }^{33}$ propicia va nova frente de conflitos entre as famílias e a corporação, que "proporcionava ensino de boa qualidade a os rapazes, filhos de civis e militares, nos Colégios Militares, e não às filhas mulheres". Inferimos que a pressão dos movimentos feministas e do meio civil se fazia sentir, se levarmos em conta que "nos anos 1980 o movimento de mulheres no Brasil era uma força política e social consolidada". ${ }^{34}$ As escolas tra dic iona is a bria m as porta s para as mulheres, e na educação física - passavam a convivercom os desafios e conflitos próprios do ensino misto, ou das próprias a ulas mistas. ${ }^{35}$ Os educadores e as educadoras debatiam a questão de aulas mistas ou separadas, e questiona vam o Colégio Militar por - tendo um ensino de tanto prestígio não se a tualiza r e aderir a o processo de abertura. A oferta de vagas às meninas nos Colégios Militares indica que 0 Exército vivia um momento receptivo às demandas das mulheres. Parte do mérito cabe à s mulheres, representando uma conquista substancial num campo marcado pelo imaginário masculino. Ratifica essa interpretação o depoimento do coronel Mosqueira, segundo o qual foi a mulher que fez o Exérc ito equiparar-se às outras armas, foi a "ascendência da mulher mesmo, a importância da mulher dentro da sociedade" que resultou na sua entrada no Colégio. 0 oficial permite-nos inferir que as pressões de 
${ }^{36}$ Dagmar Estermann MEYER, 2003, p.12.

37 Hoje, 12 Colégios Militares oferecem educação a mais de 14.000 jovens de ambosossexos, $37 \%$ dos quais do meio civil. Os sítios ofic ia is dos Colégios falam em alunos, e não mencionam alunas.

38 Proposta Pedagógica do Colégio Militar. diferentes segmentos da sociedade civil porabertura tinham no movimento das mulheres uma referência definida. Tra tava-se de um contexto emblemático, no centenário do Colégio, para gestos de receptividade aos clamores das famílias, que pugnavam porigualdade de oportunidades para filhos e filhas nas escolas do Exército de grau fundamental e médio. As expressões "ascendência da mulher" e "importância da mulher dentro da sociedade" evocam mulheres reais, de prestígio, cujas vozes e atos contribuíam para mudar modos de pensare agire abriam novas instâncias de usufruto dos direitos de cidadania, a colhidos na Constituição de 1988. Segundo essa interp retação, as a ções dos movimentos era m efetivas, no sentido de que iam além de "compreender e explicar a subordinação social e a invisibilidade política a que as mulheres tinham sido historic amente submetidas". ${ }^{36}$ Os Colégios Milita res abriram suas portas para o ing resso da juventude feminina de forma tímida, com 30 vagas para a quinta série, para depois o fazerem sem qualquer tipo de restrição. ${ }^{37}$

Pode-se avaliara importância que asfamíliasdavam ao ingresso das filhas no Colégio pela decisão de as submeterem a retomo de séries mais adiantadas para a quinta série. Muitas vezesa decisão de lutar por uma vaga materializava um projeto das famílias, com anuência das filhas, quer pelo ótimo nível de ensino, quer pelas oportunidades excelentes para a prática do esporte: "eu queria mudar de colégio [...] pela parte esportiva, porque eu sempre gostei muito de esporte".

Se o esporte empolgava, o mesmo não se dava com algumas outras práticas: era duro habituar-se aos desfiles, às marchas a o sol e aos ritua is relacionados ao "desenvolvimento de a titudese a incorporação de valores, a ssegurando a formação de um cidadão patriota, disciplinado, cônscio de seus deveres, direitos e responsabilidades". ${ }^{38} 0$ conflito se avolumou com os treinamentos dos desfiles para a primeira formatura geral, que se iniciaram duas semanas antes de começarem as aulas. As alunas estranharam o regime: "de repente você fic ar marchando no sol do Rio de Janeiro, a qui... a qui..., era uma coisa de maluco". É o que elas hoje dizem, mas não há registro de que questionaram o comando, antes se esforçaram por demonstrar que eram capazes de incorporar a identidade militar e dominar as práticas associadas o ma sculino. E foram participand o dos vários ritua is militares, para a a quisição dessa identida de, em diferentes solenidades, para elas inesquecíveis. Primeiro, a entrada solene pelo portão principal do Colégio, para a abertura oficial do ano letivo e a apresentação das 
${ }^{40}$ Ma ria do Camo SARAIVA, 1999.

${ }^{41}$ O Regulamento dos Colégios Militares (R/69) prevê (Art. 4의 que "A ação educacional desenvolvida nos Colégios Militares é feita segundo valores, costumes e tra dições do Exérc ito Brasileiro e tem como metas gerais, em sua proposta pedagógica: I - permitir a o aluno desenvolver atitudes e incorporar valores familia res, sociais e patrióticos que lhe assegurem um futuro de cidadão patriota, cônscio de seus deveres, direitos e responsabilidades, qualquer que seja o campo profissional de sua preferência; [...] VI - estimular o aluno para a saudável prática de atividade física, buscando o seu desenvolvimento físico e incentivando a prática habitual do esporte; e VII - despertar vocaçõespara a carreira militar". 42 Kathryn WOODWARD, 2005.

43 BOURDIEU, 1999. novas turmas, em formatura geral. ${ }^{39}$ Para as atividades acadêmicas, as 30 alunas foram distribuídas em cinco turmas de quinta série, com seis alunas em cada turma. Tratava-se, portanto, de experiência de turma mista, nas disciplinas de conteúdo intelectual, o que indica avanço da proposta pedagógica do Colégio e uma das razões de sua modemização, e na educação física, em sintonia com astendências e orientações pedagógicas da época, no que concerne a questões de co-educação, ${ }^{40}$ distribuição de meninos e meninas em turmas mistas ou separadas por sexo. A proporção diminuta de meninas em cada sala favorecia-lhes a absorção das normas, valorese princípios a ndrocêntric os de conduta da escola, mas fazia destacar-se o aspecto de minoria. Em ma rço, elas vivenciavam mais um ritua I militar: vestiram pela primeira vezo uniforme militar concebid o especific a mente para elas - saia-calça e camisa cáqui com frisos vermelhos, da cor da boina. Em maio, foi a vez do último ritual de iniciação: passaram novamente pelo portão principal do Colégio, agora batendo continência, fardadas, como os dema is a lunos da escola. Estava em curso o processo de identific ação, hiera rquização e d isc ip lina riza ção dos corpos e das mentes pelo concurso das instituições educacional e militar, em relação de interd ependência. ${ }^{41}$

A juventude feminina passou por uma fase de enc anta mento inic ial, no convívio com um contexto diferente do seu: "a gente chegou deslumbrada, muito feliz da vida, achando que aquilo ali ia ser um paraíso". Entretanto, o esta do de deslumbramento durou pouco, ela seram meninas imaturas, que não estavam prontas para conviver com os desafios e surpresas de uma realidade diferente: "a gente não tinha ma turida de nem ma líc ia sufic iente para saberque aquilo ali, para virar um paraíso, a gente tinha que ter cuidados, entendeu?" O enunciado "a gente tinha que ter cuidados" aponta para um processo de objetivação natura liza da do deverser, que reava lia, rea na lisa, red esc reve e ressignifica aspreocupações, temores, cautelase pressões que vivenciaram na época, em seu processo de identificação ${ }^{42}$ com os códigos de comportamento da escola.

Portanto, "a gente tinha que ter cuidados" está a ncora do na memória de dificuldadese desafios que elas experimentaram no momento inicial de sua inserção naquele contexto, quando ainda não tinham representa ções consolida das so bre o habitus do Colég io, ${ }^{43}$ e em que todas as instâncias eram referidas como merecedoras de cautela: "o cuidado era com todo mundo". Algumas demoraram mais, outra menos, para 
44 Stephen R. STÖER, António M. MAGALHÃES e David RODRIGUES, 2003. aprender a conviver nesse ambiente, criando táticas e artimanhas de sobrevivência no universo masculino. Elas interpretam criticamente o entorno de seu ingresso na escola ao referir que, durante o processo de inserção e estabilização de sua presença nos diferentes espaços do Colégio, várias mudanças na forma de tratamento foram operadas pelos militares, que "tinham medo de falar com a gente, não estavam preparados para receberem meninas... nessa fase de mudança". A educação para militar, que confere a o Colégio um caráterpreparatório para os passos sub seqüentes da ca rreira milita r, a dequava se ao ideário masculino e ainda não se adaptara à realidade feminina. Portanto, o processo de aquisição de nova sidentida des foi recíp roc 0 . Coube às alunas incorporar gestos, práticas e discursos do novo entomo. Aos militares coube aprender a lidarcom as alunas.

No comando e no corpo docente do Colégio instalara-se novo tipo de cuidado: cauteloso, precavido, diligente e desvelado, com tratamento diferenciado, no esforç o de se a justa ràs ca ra c terístic as da s a luna s. Ela s era m pré-adolescentes, várias já tinham passa do pela menarca, e o segmento docente masculino não estava preparado para lidarcom questões e tátic as femininas, a exemplo de cólica e menstruação como justific a tivas para a usentar-se das a tivida des físic as de na ta ção. No disc urso e na sa ções, a té então, circulavam disciplina, tenacidade, firmeza, lealdade e respeito. A escola defrontava-se com o desafio de lid a r com pessoas de identid a de diferente, a tentas a os pormenores do contexto, que valoriza vam o engajamento emocional do raciocínio, via m as questões étic as em termos de responsabilidade e se esforça vam em manter vínculos interpessoais. A escola cedo constatou que falhava a estratégia de transferir para a companhia de alunas o a pa ra to pedagógico e disc iplinarconsolidado no tra to com os homens. Teve de aprender a comandar pessoas de identidade distinta, provindas dos "novos movimentos socia is" referidos por Stöer, e conviver com essa nova ontologia social. ${ }^{44}$

Do relato dos três educadores depreendem-se marc as de insegurança qua nto à sestratégias para conduzir as alunas e relacionar-se com elas. Afirmações como as de que a relação "não foi, a ssim, muito contraditória em relação a muitos professores aqui dentro" e "não foi tão a gressiva assim" sugerem que a expectativa era encontrar ma is problemas de rela c iona mento, integ ração e conduta. Pressupunham-se mais a gressividade e rebeldia.

As vantagens da nova convivência não se fizeram esperar. O Colégio melhorou, humanizou-se e se refinou em seus princípios de hierarquia e disciplina, temperados 
${ }^{45}$ BERNSTEIN, 1990.

${ }^{46}$ RORTY, 1994. com a solidariedade, graças à presença das alunas. Segundo Mosqueira, sua relação inicial com as alunas "foi sensacional". Como membro do mais alto escalão da hierarquia, ele a tribui a melhoria das relações a c caráter saudá vel do novo contexto: "quem viveu o Colégio como homem, só homem todo dia, e viveu a fase da primeira turma, com essas 30 meninas, e hoje vivem aí as alunas, espalhadas por todas as séries, a gente vê que o Colégio mudou, mudou o próprio relacionamento dos alunos entre si, o próprio comportamento, a té disciplinar". Os rapazes tornaram-se mais cordia is, a cortesia ganhou espaço, gestos brutos, palavrões e palavras rudes perderam prestígio. Manifestações da violência física e simbólica passaram a ser coibidas, ou desencorajadas. Designado para comandara primeira turma de alunas, ele encarou a a tribuição como uma "missão" especial, o que denota o quanto a experiência de dirigir a juventude feminina empolgava os militares e Ihes conferia status na carreira: "uma grande honra [...], foi até um prêmio, porque a maioria dos ofic ia is estava pleiteando essa função". No grupo ap to a assumir tal responsabilidade convivia-se bem com os "cuidados" e riscos do cargo. Na proposta pedagógica do departamento de ensino do Exército exercitava-se a recontextua lização pedagógica da escola, na linha das idéias que Basil Bemstein ${ }^{45}$ então propunha, em que novos códigos de controle se ajustavam aos interesses e especificidade de grupos minoritários, a té então não a tendidos em sua demanda poreducação de qua lidade, com respeito diferenciado a os interesses e características de cada grupo. Estava em curso a consolidação de uma proposta modular, que se tentava ajustar a os ditames de cada segmento. As a luna s contribuíam, nos termos de Rorty, para um mundo mais belo, menos cruel, ma is solidário. ${ }^{46}$ Esta va criado o contexto pa ra a co-educação, pa ra a troca de saberes e o aprendizado de novos dizeres.

As a luna s ficaram em evidência, durante boa parte de seu percurso acadêmico, mas sobretudo no primeiro semestre, quando sua presença na escola era novidade; segundo reg istros na imprensa, elas foram responsá veis por uma imagem renovada do Colégio. O Globo, em 25 de abril de 1989, anotava o processo de rejuvenescimento da veneranda instituição, com termos polares, que se complementam e artic ula m: "Colégio Militar, a a usterida de com jeito jovem aos 100 anos". A repórter Elizabeth Marins a firma va que a experiência está dando certo: "A presença feminina na instituição ocorre sem problemas de a daptação". Ela enfatiza o processo integra tivo, que a va lia, naturalmente, como livre de discriminação: "Sem 
preconceitos, ele completa seu centenário com garotos e garotas dentro de seus muros".

\section{Tratamento e expectativas de convivência}

Segundo a informante Márcia, no começo as alunas eram consultadas sobre qualquer medida a ser implementada e que dissesse respeito a elas. Por um lado, sentia m-se "protegidas" com esse tipo de atitude: "a gente sentia um cuida do muito grande, com relação a gente, né?" O comando exigia supervisão contínua. A inexperiência no tra to com a diferença fundada na ordem do gênero e a diligência para não errar criavam um clima de controle múltiplo, sem espaço para qualquer tipo de descuido: "parecia que todo mundo estava pisando em ovos, entendeu?" Esse tratamento, a o mesmo tempo firme e maleá vel, destoa va do c a rá ter a nd rocêntrico do milita rismo brasileiro, com a hierarquia rígida, a disciplina explícita, o regulamento transparente e o cumprimento das determinações superiores, a que estavam submetidos os rapazes.

Flá via sintetiza as tensões e intenções dos responsáveis por sua educação. Ela não se sentiu "disc rimina da por ser mulher dentro do Colégio"; a ntes, viu uma atitude de certa "proteção". Tal atitude Ihe parecia "um pouco patemal", mas natural: "achei que sempre o objetivo foi beneficiar a gente, atender a gente". A expressão "um pouco paternal" naturalizava a tutela, indiciada em "o objetivo foi beneficiar": com foco no controle, suavizado pelo modo de exercê-lo, e na manutenção da dependência pela proteção. Ela, entretanto, talvez sem atentar para os mecanismos de dominação, interpreta o gesto um pouco patemal apenas como sinal de benevolência, com o objetivo de beneficiar as alunas. No momento do ingresso, a proteção às alunas era explícita: o ambiente era de isolamento, com um local reservado para elas no recreio, em face de possíveis desmandos dos alunos mais antigos: "a gente não podia sair de lá para não ter conta to com os alunos ma is a ntigos, ia $m$ a va nça rem cima da gente, nã o sei, a gente fic ava ali meio isolada". O depoimento dificulta saber se a cautela era de ambos os segmentos, educadores e alunas, ou apenas desses, com referência aos riscos do conta to com os a lunos mais a ntigos. A medida extrema do isolamento é indicativa de problemas e conflitos não trivia is no relacionamento entre alunos e alunas. A opção pelo isolamento pode ser interpretada como concordância delassobre esse recurso, para protegê-las de investida por parte dos rapazes maiores.

664 Estudos Feministas, Florianópolis, 14(3): 655-680, setembro-dezembro/2006 
47 Vide LOURO, 2003; BOURDIEU, 1999; MOSCOVICl, 2003, para indícios da dominação masculina em frases feitas, ditados, chistes, denominaçõese epítetos. 48 Vide Tomaz TADEU DA SILVA, Kathryn WOODWARD e Stuart HALL, 2005, sobre identidade e diferença.
Os professores estavam divid idos, em face da nova empreitada educativa. Um grupo era indiferente a elas, outro olhava "atravessado" para elas, enquanto a grande maioria dos professores aplaudia a novidade. Estes eram partic ula rmente cuida dosos com elas e lhes ofereciam um tratamento singular. A esse grupo pertenciam Edvan e a lguns colegas que, no começo, estavam incertos sobre como tratá-las e - ancorados em sua vivência familiar transferia m estratégias de sua experiência paterna. Cada aluna "era como se fosse, sabe, uma filha a mais, que a gente tivesse que tratar com um pouco mais de carinho... a s a titudes um pouco ma is sutis". A segunda imagem para objetivá-las é a de bonecas: "Elas rea Imente eram tra ta das como... as bonecas do Colégio Militar". A comparação, precedida de longa pausa, é sintomática de cuidado em face da diferença: como lidar com a fragilidade, a delicadeza e outros atributos do mundo feminino, aqui objetiva do por um brinquedo? Eles estavam acostumados a educar e a conduzir alunos e agora se sentiam em situa ção de desa fio qua nto a os proced imentos a dequa dos para conduzir as alunas. O comandante Mosqueira representa as alunas com traços nebulosos, tanto na quantificação e adjetivação de cuidado quanto na objetiva ção. Dizque o corpo docente as tra ta va "com todo cuidado, a té cheio de dedos dema is [...] elas eram nossos xodozinhos, entendeu?, na época a té existia uma preocupação muito grande, e a inda tem". O uso diminutivo do termo "xodó", da bacia semântica dasrelações afetivas, e a gradação de cuida do enfatizam a oposição pequeno versus gra nde, frá gil versus forte, objeto versus a gente, além de conotarem ambivalência no termo da objetivaçã o. ${ }^{47} \mathrm{~A}$ natura lização da diferença fica evidente: "agora é minha opinião pessoal, eu a cho que nós não somosiguais, somos biologicamente diferentes [...] e cada um dentro de suas característic as tem que chegar lá". ${ }^{48}$ No afã de acertar, os professores tratavam as alunas com algum favoritismo, conforme as palavras delas: "faziam a té alguma distinção das meninas, tratavam até de forma mais, vamos dizer, aceitavam mais os erros, do que aceitavam dos alunos, né?" O cuidado, proposto por Gilligan como encargo e a tributo feminino, era agora exercitado por eles, homens, no tra to com as alunas.

Em relação a os rapazes, nos conflitos inicia is de convivência e interação acirravam-se questões de identidade, com seus componentes de pertencimento e exclusão. Elas eram tratadas como estranhas no nicho militar: "no começo isolaram a gente". Mantidas em local reservado, sentiam-se "bichos do mato". Os rapazes estavam divididos. Alguns achavam muito bom existirem 
49 Vide WAGNER, 2002, para intersecção e conflito nas representações de subgrupos. meninas no Colégio, havia outros "que tavam a fim de a rranjar uma namorada, e meninos que esta va $m$ a chando interessante, diferente, legal, entendeu?" Por fim, havia o grupo dos hostis, que as rejeitavam e queriam excluí-las daquele lugar: ali "não era lugar de mulher [...] tinha que continuar só homem mesmo". Esses verbaliza vam a na tura liza ção da a ssimetria na a tribuição de oportunida des a meninose meninas. Reagiam à quebra da privacidade e dos privilégios de seu mundo masculino, com suas regalias, que era invadido. Agora, era preciso alterar as práticas masculinas.

A atitude mais hostil vinha dos alunos ma is velhos, que já estavam no ensino médio, e nos qua is se tornava ma is evidente a "amnésia da gênese" do privilégio masculino. Não se conformavam com a perda da exclusividade e com a inevitabilidade de compartilharem o espaço com as mulheres. As palavras denotam forte consciência identitária, articulada ao senso de teritório: "cai fora, é, sai fora, isso aqui não é lugar pra vocês". O direito exclusivo é apresentado como atemporal, e não adquirido num momento e contexto histórico específico, da fundação do Colégio, um século a ntes (1889). A revolta contra a perda desse direito é evidência da necessidade de historicizar o processo de construção de assimetrias no acesso a os benscultura is e ma teria is, na ordem do gênero. Nesse contexto complexo, diferenciado e conflituoso, as alunas foram a ssumindo diferentes atitudes em face das pressões e injunções. No início o grupo das 30 parecia homogêneo, mas com o passar do tempo, em vez da unida de nas representa çõese práticas, verific aramse conflitos nas expectativa s e comportamentos. ${ }^{49} \mathrm{~Pa}$ ra um subgrupo, tipificado por Clarice, o fato de o Colégio ser um quartel, com seus ritua is regulares, periodicamente repetidos, começou a ficar pesado. O treinamento e a execução da ordem unida para as formaturas gera is passa ram a perder sentido: "na sétima série eu já odiava, pensei várias vezes em sair do Colégio, porque não via sentido nesse militarismo às vezes 'burro', era muita coisa sem sentido". Referia -se à monotonia da repetição dos ritos do cotidiano militar: "você começa a não ver ma is sentido, perde o significado, então você começa a questionar". Vieram à tona as táticas, subterfúgios e dribles às normas, de que fala Bourdieu. Ela não saiu do Colégio, mas começou a "matara formatura e a não levartudo tanto a sério". Superou suas dificuldades em face dos ditames militares, reinterpretando e transgredindo as regras, para assim permanecer na esc ola e podercontinuarcom a parte esportiva. Havia também o subgrupo que assumiu prontamente a nova identidade e integrou-se 
50 Essa conquista destoa parcialmente da previsão de BOURDIEU, 1999, de que as mulheres brilham em funções estreitamente associadas ao labor familiar.

${ }^{51}$ J ORNAL DO BRASIL, 1993, p. 5356. completamente; não questionava as regras, antes as cumpria fielmente para se destacar, identificado com os idea is do Colégio. Esse subgrupo é representado por Márcia: "que eu gostava de terque me submeter a uma... disciplina, que eu gostava de ter regras pra seguir, que eu gosta va que essa s regras func iona ssem pra que eu pudesse me destacar nelas". Ela cedo constatou que as pessoas que "se destacavam na parte intelectual tinham seu valor, tinham o seu destaque, até a hora de sair do Colégio, e isso mexia comigo [...] achei isso muito motivante, entendeu?". Avaliou seu potencial e se destacou: demonstrou exc elente disciplina intelectual, que equilib rou com invejável desempenho esportivo, que "foi tudo pra mim, eu sabia que tinha minhas simita ções, então eu queria compensarna parte físic a, porque embora tivesse um peso menor, né?... era aquilo que me levantava, no final". Comprometida com o ideário da escola e com as tra dições milita res, tornou-se exemplo dentro da instituição.

Em 1993, no começo do ensino médio, deu-se a iniciação às Armas, a que a lunos e a luna sascendiam, por nota ou por escolha. Foi então que elas aprenderam os fundamentos e as singularidades de cada arma: a Infantaria, com aprendizagem básica do manejo de fuzil; a Comunicações, com fundamentos básicos do rádio a madorismo; a Artilharia, com o manejo de canhões; e por fim a Cavalaria, com os fundamentos da equitação. Uma informante escolheu a Artilharia; duas, a Cavalaria. Tratava-se de rito de passagem para a fase propriamente preparatória para o ingresso em outras modalidades de formação, a pós a conclusão do curso médio. Foi como se tivessem "revivido a quinta série no primeiro a no [...] por causa do unifome que é diferente [...] foi outra badalação", novamente com o assédio da imprensa, ocasionado pela conquista de um dos últimos espaços masculinos no Colégio. Um dos critérios para ingressar na Cavalaria era possuir as melhores notas na primeira série, a lém da habilidade na condução do cavalo, o que era verificado em a valia ção prática. ${ }^{50} \mathrm{~A}$ imprensa foi generosa no elog io à diferença, em reportagens assinadas por mulheres. A jornalista Andréa Magalhães, em O Globo - Tijuca em 6.7.1993, destacou o momento vivido por Márcia como "primeira aluna da Cavalaria". Esta declarou então que, para venceros preconceitos e poder escolher essa Arma, "basta mostrar competência". A reporta gem registrou que a aluna sonhava com o ingresso no Exército e em cursar "uma Agulhas Negras para meninas"; e finalizou com "a farda cáqui e vermelha ajuda a camuflar seus dezessete a nos". A Revista de Domingo do J ornal do Brasil ${ }^{51}$ dizia que as pioneiras estão "perfeitamente integradas; elas 
52 No plano do domínio da língua, podemos verificar isso nos estudos da sociolingüística. As pesquisas conduzidas em diferentes línguas, em distintas comunidades, comprovam que as mulheres estã o ma is próximas do padrão prestigia do, enquanto os homens têm menos domínio das regras da língua culta. organizam festas, solenidades, participam dos desfiles, a venturam-se em competições e a té comandam turmas".

No desempenho aca dêmico, as menina s revelaramse melhores do que os meninos. Reforçando um contraste que se verifica, comumente, quernas disciplinas da escola em geral, querno domínio das regras da língua padrão, a repórter afirmava: "os garotos estão tendo que aturar, as meninas têm as melhores notas". ${ }^{2}$ Segundo o coronel Arume, a qua lid a de "excepcional" das alunas que entra ram no concurso de admissão resultou de uma seleção muito boa. E acrescenta: "o pessoal elogiava muito, achavam que a forma como elas se portavam... né..., a educação, tudo" propiciava um movimento positivo de continuidade feminina. As a lunas demonstra ram que a opção do Exército, pela inserção feminina no Colégio, dera certo, pois elas se to ma ra m figura s exempla res dentro $d a$ instituição.

As alunas tinham desempenho excelente, eram elogiadas pelo comando e desestabilizavam as hostes masculina s. Segundo a sreporta gens, o sucesso da sa lunas despertava "até ciúmes" na a la masculina. Verificavamse ma nifestações de revolta dos a lunos e de queixa contra a imprensa: "No a niversá rio do centená rio do Colégio, a imprensa deu destaque para elas; esqueceram que nós, homens, levamosnas costas a fama da instituição durante todos estes a nos". E voltava o velho refrã o: "Ela s tira ram a liberdade dos garotos". Eles estavam tendo dificuldade em alargar o círculo do nós, para abrigar pessoas de identidade diferente. Entretanto, a grande maioria as a plaudia, com gestos de a poio: "A presença delas tomou o Colégio ainda melhor".

A entra da das alunas na Esc ola Militarfoi um ensaio, e não um sinal de abertura plena do Exérc ito às mulheres. A expectativa era que, após a conclusão das atividades escola res nos níveis fundamental e médio, elas pudessem ingressar na escola preparatória do Exército e depois em sua academia militar: "acho que elas acreditavam que quando terminasse o segundo grau aqui na época [...] que - Exército já estivesse preparado para recebê-las, acho que essa foi a expectativa". Infere-se que junto aos professores era grande a expectativa quanto à projeção do futuro delas no campo militar, poisa nega tiva do Exérc ito em a tenderà sdemandas redund ou em revolta das a lunas, a valiação crítica da sociedade civil e queixa dos professores do Colégio contra a pressão das próprias alunas, agora objetivadas como "elefantes": "a gente cria os elefantes e deixa eles crescendo, depois eles pisam na gente". Continua fechado o seu acesso à Academia Militar das Agulhas Negras, ao Colégio Naval e à Escola Naval. 
${ }^{53}$ Notas da observação participante.

${ }^{54}$ LOURO, 2002.
${ }^{55}$ O Colégio Militar do Rio de Janeiro possui um parque esportivo que conta com uma piscina olímpica e outra para adaptação, uma pista de a tletismo com $372 \mathrm{~m}$, três quadras externas uma para handebol, outras para basquetebol e voleibol), um campo de futebol, um ginásio poliesportivo e outro ginásio para ginástica de trampolim e olímpica, sala de judô, sala de esgrima e sala de musculação.

${ }^{56}$ Ating ir o limite máximo de pontos perdidos implic ava desligar-se do Colégio.
Elas têm a cesso a o Instituto Milita rde Eng enharia, a o Instituto Tecnológico da Aeronáutica e à Aca demia da Força Aérea.

\section{A inserção das a lunas na cena físico- desportiva do Colégio}

As alunas sabiam que ultrapassados os primeiros desafios - de identific ação, a daptação e superação do preconceito de gênero - cabia demonstrarem, no grau médio, suas habilidades esportivas. As a tividades efetua das nas aulas de educação físic a concorria $\mathrm{m}^{53} \mathrm{com}$ a prática de atletismo, natação, basquetebol, voleibol, handebol, esgrima, judô, ginástic a olímpica e tênis de mesa, realizadas de forma mista. Ginástica rítmica e dança eram privativas das a lunas, enquanto somente os rapazes jog a vam futebol, o que em parte confirma Louro, ${ }^{54}$ para quem a constituição da identidade de gênero nas a ula sde educa ção físic a fic a ria ma is "evidente"; a ordem do discurso biológico, para a manutenção da saúde e da higiene, seria a justificativa para a separação das turmas masculinas e femininas.

A educação físico-desportiva feminina possuía c a rac terístic a s distinta s das dema is a tivid a des a c a dêmic as e para milita res do Colégio. O comand o e o corpo docente não manifestavam nem permitiam qualquer tipo de proteção ou condescendência nas aulas de educação físic a e na atividade esportiva. Antes, favorecia a espec ia liza ção e estimula va a competição, em condiç ões igua is para meninase meninos. Para as alunasa educação física era "boa, porque permitia a você conhecer as modalidades e lhe dava chance de se especializar em a lguma coisa". A infra-estrutura do Colég io contribuía para tal: "pouquíssimos colégios no Rio de Janeiro têm a infraestrutura que o Colég io Militartem para a parte esportiva". ${ }^{55}$

O curríc ulo previa do is testes físic os por ano, para os qua is o corpo disc ente deveria treinare dos qua is resulta va a nota da educação física. Para o segmento feminino, o teste consistia em provas de 50 metros rasos, salto em distância, salto em altura, teste de 12 minutos, número máximo de flexõese abdomina is em um minuto e 50 metros de nado crawl. Cada estudante deveria conquistaro melhor resulta do possível, o qual era direciona do para uma tabela de pontos, com a qual se confeccionava a média, juntamente com a freqüência às aulas. Essa nota influenciava no sistema de nivelamento de divisas utiliza do pelo Exérc ito e pelo Colégio Militare compunha a nota de c omporta mento. ${ }^{56}$ Louro a tribui à saula s de educa çã o físic a no contexto escolar questões ditas como inerentes a sua prática: a constante competição nas práticas esportivas, 
${ }^{57}$ LOURO, 2002, p. 75. a avaliação, observação e comparação de alunos e alunas, explicando o que não se pode negar: "que sero melhor, no esporte, pode representar, especialmente para o rapaz, um valor, símbolo de masculinidade". ${ }^{57} 0$ desempenho esportivo das alunas parece sugerir outra pauta simbólica.

A partir da 7 a série, alunas e a lunos eram livres para selecionar e praticar o esporte com que mais se identificassem. O Colégio contava com escolinhas comunitárias para o corpo discente e para jovens da comunidade, fora do horário das aulas, com as moda lid a desesp ortivas pratic a das nas a ulas de educ ação físic a. A a desão a o esporte revelou vocações: "se hoje sou professora de educação física, é... tudo isso começou no Colégio Militar, com a chance que eu tive de estar mais perto do lado esportivo". Ala va nc ou ta mbém a a uto-estima: "aqui eu comecei a gostar, curtia realmente a educação física, o esporte pra mim foi muito bom, porque me deu uma coisa de auto-estima muito grande". A busca da nota máxima tornou-se obsessiva: "não era pra ninguém, eu ficava, eu pulava na piscina, eu só pensava assim, eu me afogo, mas eu chego lá com dez". O objetivo era tirar a nota máxima em todas as provas físicas. À pa rte intelectual elas aliaram a parte física. Identificadas com a escola e motivadas, assimilaram-lhe o ideário militar de vencer, superar-se, daro sangue pela conquista.

\section{o desempenho das alunas em competições esportivas}

O resultado previsível dessa dedicação foi que as a lunas brilharam no esporte, de modo singular. A inserção feminina nas atividades esportiva s competitivas inic iou-se com as olimpíadas intemas, intra-série, a té a 7ạ série do ensino fundamental. $\mathrm{Na} 8^{a}$ série elas constituíam a equipe da 4a Companhia e competiam com as Armas do ensino médio: Cavalaria, Infantaria, Artilharia e Comunicações. Era a prestigiosa "Olimpíada das Armas". As competições eram rea liza das nas moda lidades pratic a das nas aulas de educação física e duravam cerca de uma semana.

Segundo dados das informantes e registros da observação partic ipante, "a O limpía da das Arma sera muito competitiva", [...] "aquilo tinha uma dimensão imensa, era a Olimpíada", ressaltando-se o empenho com que as torcidas e equipes se orga niza vam e iam assistir a os jogos, disputando ponto porponto os resulta dos das competições. As rivalida des eram inevitá veis, bem como "o preconc eito por serde uma Arma e não ser de outra". Quando se tra tava de defender o Colégio, de garantir "a representatividade 
${ }^{58}$ Revista A Aspiração, 1995/1996, p. 5. O coronel Pinheiro era procedente da Escola de Comando e Estado Maior do Exército. do Colégio, qua ndo a competição era extema, já era outra coisa, uma coisa totalmente diferente, porque tinham as equipes que eram formadas por membros de qualquer Arma, independente do que fosse". O "espírito de corpo", rela ta d o pelas a luna snesses momentos esportivos, permitenos verificar o quanto elas se adaptaram, como se apropriaram da identidade do Colégio, e como incorporaram de forma excelente os ideais e as normas nele empregadas.

A partir da 8a série elas passaram a representar o Colég io em diversos eventos competitivos. Em 1993 a coa utora deste estudo passou a atuar regularmente como professora e técnica dessas alunas, e pôde constatar o seu empenho cotidiano, com engajamento total no desporto escolar. Assumiu então o comando o coronel de Infantaria Codevila Pinheiro, ${ }^{58}$ que orientou o Colégio para as competições interescolares e organizou seus quadros masculinos e femininos para uma participação efetiva.

Segund o testemunho docente, era visível o empenho das a lunas em a perfeiçoar-se na prátic a dosesportes: "elas participavam, a lém de atletismo, esgrima e judô, de todos os esportes que nós podemos citar aqui, elas tinham ta mbém a parte de dança e GRD, elas tinham mais eventos esportivos do que os próprios alunos". Elas superaram as expectativa s e foram co-responsá veis pelo êxito do Colégio nas competições esportivas. Em 1994 a escola conquistou o seu primeiro título estadual geral, no XII Campeonato Intercolegial. Nessa competição houve vários resultados expressivos nas modalidades individua is, masculinas e femininas: dois primeiros luga res gera is no atletismo e em natação, um segundo lugar geral no judô e um terceiro lugargeral no tênis de mesa. A 1 ạ Copa Fanta foi a segunda competição em que o Colégio obteve resultados expressivos, que ajudaram a recuperar seu parque esportivo. Nessa copa, a Secretaria de Esporte e Lazer do Esta do do Rio de J a neiro premiou com 20.000 rea is a escola campeã geral, além de oferecer material esportivo completo para as equipes que obtivessem a primeira colocação. O Colégio obteve o primeiro lugar geral no voleibol masculino e manteve a primazia dos pontos em modalidades individuais, com participação feminina e masculina, com os primeiros luga res gera is no atletismo, na ginástica olímpica e no ciclismo.

Em 1995 o Colégio conquistou o bicampeonato geral do Intercolegial. A partic ipação feminina foi relevante nas competições individua is de a tletismo, nata ção, judô e tênis de mesa. Nas modalidades coletivas, as alunas contribuíram na pontuação, com o oitavo lugar geral do basquetebol feminino e o quarto lugar geral do handebol 
${ }^{59}$ A c 0 -autora deste trabalho foi, nesse período, a única técnica feminina a atuar com treinamentos de modalidades esportivas individuais ou coletivas.

${ }^{60}$ MOURÃO, 2003, p. 143. feminino, o que resultou na conquista do XIII Intercolegial. Nos J ogos das Escolas Públicas Federa is, o Colégio Militar sagrou-se campeão geral. Pela primeira vez o voleibol conquistava o primeiro luga rem uma competição. Trunfa va a juventude feminina, num campo de confronto originariamente masculino; maso mérito da vitória a tribuíase sobretudo a o comandante do Colégio, reforçando-se a tese de Bourdieu.

Clarice começou a se dedic ar ma is à s competições na $8^{a}$ série, praticando voleibol, além de participar das competições intemas. Envolveu-se com os treinamentos de atletismo, ${ }^{59}$ fora do horário de aula. Foi premiada como a melhoratleta do Colég io em 1994 e 1995, recebendo placas alusivas a suas conquistas esportivas. No Intercolegial de 1995, Flávia obteve a medalha de ouro na prova de salto em altura, categoria livre não-federada, e a de prata no revezamento $4 \times 100 \mathrm{~m}$. Ela diz que se tomou uma pessoa ma is plena e confiante, o que contribuiu para "ganhar medalhas pra somar, pra resultados do Colégio". Márcia executa va treina mento semanal para as solenida des ofic ia is e atuava com a equipe de dança que realizou a abertura do Intercolegial de 1994 e 1995, conquistando para o Colégio, nos dois a nos consecutivos, a pontua ção máxima e os títulos de melhores desfiles de abertura dos jogos. Em síntese, nas competiç ões esportiva s intercoleg ia is de 1994 e 1995, a lunase a lunos da escola brilha ram a cima da média, em decorrência da estrutura ção esportiviza nte utiliza da pela seção de educação física, e sobretudo do suporte e apoio contínuos do comandante e da professora que se dedicava, em horário fora das atividades regulares, para desenvolver o potencial atlétic o e esportivo das atletas. Era consensual a competência esportiva do Colégio, tanto na olimpíada intema como nos jogos intercolegia is.

A trajetória esportiva do Colégio Militar ilustra parcialmente a avaliação de Ludmila Mourão ${ }^{60}$ que, analisando a política do esporte nacional, refere jogos marcados pelo "alto grau de elitismo, seletividade e competitividade [...] que repetem a façanha dos clubes em torneios loca is e regiona is [...] Muita s esc ola s brasileiras func iona m como clubes, no que diz respeito a o modo como conduzem o esporte, centradas [...] na competição". A diferença está em que alunos e alunas do Colégio Militar, seguindo osprincípiosda proposta pedagógica, inic ia vamse nos esportes como uma prática para a vida, e não apenas para as competições. 


\section{Cuidados e diferenças na cena acadêmica e esportiva}

Vimos como no momento do ingresso das alunas o cuidado no tratamento da diferença perpassa o discurso discente e docente no Colégio. Ambas as categorias se interpenetram na objetivação, identificação e reconhecimento das diferenças e incorporação de disc ursos e prátic as identitá rias. Na perspectiva das a lunas, no começo era prec iso havercuida dos especia is com to do mundo, a começar pelos ra pazes ma is velhos, bem como com professores e oficiais. Para o corpo docente, urgia red obrar o cuida do com as a lunas, objetivadas como seres diferentes, especiais, xodozinhose bonecas. Cabia cuidar delas, dado que se a presenta va m como pessoas diferentes, num contexto hostil, ou pelo menos nã o fa miliar. Para a mbos os segmentos, cuidar e suas variantes ancoravam-se no espaço-tempo específico do a to comunicativo e da trajetória de inserção. À medida que elas se integravam, diminuía o cuidado, a ponto de as mesmas se revelarem estudantes e atletas modela res, e de supera rem os rapazes em a tivida des associa das a o cotidiano militar.

Num primeiro momento cuidar parece polissêmico e indetermina do, mas a a nálise dos contextos em que suas variantes ocorrem permite uma compreensão mais nítida da bacia semântica em que as nuances de sentido se estabilizam e gramaticalizam. ${ }^{61}$ A raiz latina cogitare continua ativa em cogitar e seus próximos: pensar, ima ginar, meditar, julgar, associa dos a atentar, privilegiar. Cuidado, por sua vez, especializa variantes como diligência, desvelo, cautela, responsabilidade e encargo. Sobrepaira às variantes o traço semântico "pôr em foco". A gramática do domínio de cuid- é sensível às condições de produção em que o termo e o conceito se manifestam, com as derivações da morfologia, e com a sintaxe de seu uso como verbo e como nome, tanto no singulargenérico, cuidado, quanto no plural cuidados.

0 estudo permite afirmar que cada subgrupo reanalisa a bacia semântica de cuid- em função de sua experiência e cautela em face do imprevisível no tra to com o diferente. Um pinçamento de registros de reações ao diferente mostra estreita relação dos usos do diferente com a exclusão e a inclusão, nos a tos de identific ação, a propriação ou rejeição de traços identitá rios, que reforçam pertencimento ou enfatizam separação. Assim as alunas, que sofreram mais direta e fortemente os mecanismos de exclusão e discriminação por serem diferentes e estarem oc upando um luga r historic a mente destina do à id entida de masculina, a valiam o quadro patema lista dizendo: "achei 
${ }^{62}$ SC OTT, 2005, p. 15.

que sempre o objetivo foi beneficiar a gente". Desc revem a escola como atenta a seus anseios e dificuldades: "a gente sentia um cuidado muito grande, com relação a gente, né?" Avaliam as ações pedagógicas como marcadas por cuidado em face do imprevisível: "parecia que todo mundo estava pisando em ovos, entendeu?" $\mathrm{E}$ para fechar esta lista, oferecem uma a valiação genérica: "a gente tinha que tercuidados". Osalunos cuidam de seu espaço e dizem que ali "não é lugar de mulher... que tem que continuar só homem mesmo", e insistem: "cai fora, é, sai fora, isso aqui não é lugar pra vocês". Os professores a firmam que "nós nã o somos igua is, somos biologic amente diferentes"; que "elas realmente eram tratadas como... as bonecas do Colég io Militar".

O diferente, que destoa do contexto e é alvo de cuidado, sustenta-se como diferente e excluído na perspectiva do outro. 0 diferente ameaça, desestabiliza, provoca reações em que cuidar, cuidado e cuidados se ma nifesta $m$. Entre as rea ções, pola riza m-se a interp reta ção do diferente como frágil, quebradiço, maleável, que necessita de cuidado e de cuidados especiais, ou como perigoso e incontrolável, objetivado no elefante, que pisa no curador. No contexto da inserção feminina no Colégio Milita r, transitar pelo universo da diferença é pisar em ovos, para tomarmos outra ima gem produzida na interação.

A a firma ção de J oan Sc ott, 62 de que "os termos de exclusão sobre os qua is a disc rimina ção está a mpa rada são ao mesmo tempo negados e reproduzidos nas demandas pela inclusão", ratifica-se na interpreta ção do quadro tenso de oposições e conflitos de interesses em que igualdade e diferença se interpenetram, e em que os cuidados se multiplicam, na tentativa de manter os dire itos de cada grupo. Podemos considerar que esta mos diante de um paradoxo entre o efeito de ações positivas e a entrada de um grupo minoritá rio em sea ra masculina. A proteção, o cuidado, para garantir o direito dos diferentes, turva a posse do direito adquirido pelos a ntigos titula res do Colégio.

Cuidado em face da diferença teve um tra tamento digno de menção, no comando e no corpo docente, com respeito à cena esportiva, em que se desta ca uma a titude construtiva, centrada na orientação e no treinamento sistemáticos para vencer os desafios e atuar no limiar do esforço, com transferência de estratégias, técnicas e táticas do treinamento de alto nível, com intenso e contínuo cuidado profissional, sem as marcas da condescendência maternal nem do autoritarismo patemal. No que diz respeito às diferenças de gênero, com foco na performance e estímulo à determinação, as 
alunas, ma is uma vez, dobraram-se inconscientemente a os dita mes and roc êntric os e deram glória e visibilida de a o comando do Colégio.

\section{Referências bibliográficas}

A ASPIRAÇÃO/COLÉGIO MILITAR DO RIO DE J ANEIRO. Entrevistas, Produções Gráfic as e Public ações Ltda. Rio de J a neiro, 1995-1996.

ABREU, Neise Gaudêncio. Meninos pra cá, meninas pra lá. 1990. Dissertação (Mestra do em Educação Física) Programa de Pós-Graduação em Educação Física, Universidade Gama Filho, Rio de Janeiro.

ALTMANN, Helena. Rompendo fronteiras de gênero: Marias (e) homens na Educação Física. 1998. Dissertação (Mestrado em Educação) - Programa de PósGraduação em Educação, Universidade Federal de Minas Gera is, Belo Horizonte.

BARDIN, Laurence. Análise de conteúdo. Lisboa: Edições 70, 1977.

BERNSTEIN, Ba sil. Class, Codes and Control. The Structuring of Pedagogic Discourse. London: Routlege, 1990. v. 4.

. "Da s pedagogias a os conhec imentos". Educação, Sociedade \& Culturas, n. 15, p. 9-17, 2001.

BO URDIEU, Pierre. "L'opinion publique n'existe pas". Les Temps Modernes, n. 318, p. 1292-1304, jan. 1973.

A dominação masculina. Rio de Janeiro: Bertrand Brasil, 1999.

BRASIL. Decreto-lei no 3.199, de 14 de abril de 1941. Institui normas gerais sobre o desporto e dá outras providências. Rio de Janeiro, 1941.

BRASIL. Deliberação do Conselho Nacional de Desporto. Sétima deliberação: regula as modalidades esportivas para mulheres e dá outras providências. Brasília, 1965.

DEVIDE, Fabiano. História das mulheres na natação brasileira no século XX: das inadequações às representações sociais. 2003. Tese (Doutorado em Educação Física) - Programa de Pós-Graduação em Educação Física, Universidade Gama Filho, Rio de Janeiro.

- Gênero e mulheres no esporte: história das mulheres nos jogos olímpicos modernos. Ijuí: UNIJUÍ, 2005.

DUARTE, Cátia Pereira. O disc urso de escolares a dolesc entes femininas sobre os critérios de seleção utiliza dos para a participação em aulas mistas de Educação Física. 2003. Dissertação (Mestra do em Educação Física) Programa de Pós-Graduação em Educação Física, Universidade Gama Filho, Rio de Janeiro. 
FERREIRA, José Luiz. As relações de gênero nas aulas de Educação Física: um estudo de caso em uma escola pública de Campina Grande. 1996. Dissertação (Mestrado em Educação) - Programa de PósGraduação em Educação, Universidade Federal da Paraíba, João Pessoa.

FIG UEIREDO, Antônio; FONTES, Arivaldo Silveira. Breve introdução à história dos colégios militares no Brasil. Rio de Janeiro: [s.n], 1958.

GIயGAN, Carol. Uma voz diferente. Rio de Janeiro: Rosa dos Tempos, 1990.

GOEயNER, Silva na V. "Gênero, Ed uc a ção Física e esportes: do que falamos quando em gênero falamos?" In: VOTRE, Seb a stião; MOURÃO, Ludmila (Orgs.). Ima ginário $\&$ representações socia is em Educação Física, esporte e lazer. Rio de Janeiro: Editora Gama Filho, 2001. p. 215-228

Bela, maternal e feminina: imagens da mulher na Revista Educação Physica. ljuí: UNIJ UÍ, 2003.

"Mulher e esporte no Brasil: entre incentivos e interdições elas fa zem história". Pensar a Prática, v. 8, n. 1, p. 85-100, 2005.

J ORNALDO BRASIL. Rio de J a neiro, a no 17, n. 887, p. 52-58, 2 maio 1993. Revista de Domingo.

KUNZ, Maria do Carmo Sa ra iva. Quando a diferença é mito: uma análise da socialização específic a para os sexos sob o ponto de vista do esporte e da Educação Física. 1993. Disserta ção (Mestra do em Educação) - Programa de Pós-Gradua ção em Educação, Universida de Federal Santa Catarina, Floria nópolis.

LOHMANN, Liliana. A inserção acadêmica e esportiva da primeira turma feminina no Colégio Militar do Rio de J aneiro. 2005. Dissertação (Mestra do em Educação Física ) - Programa de Pós-Graduação em Educação Física, Universidade Gama Filho, Rio de Janeiro.

LOURO, Guacira. Gênero, sexualidade e educação: uma abordagem pós-estruturalista. 4. ed. Petrópolis: Vozes, 2002.

LOURO, Guacira Lopes; NECKEL, Jane Felipe; GOELLNER, Silvana Vilodre. Corpo, gênero e sexua lida de: um debate contemporâneo na educa ção. Petrópolis: Vozes, 2003.

MANC HETE. Rio de Janeiro: Bloch Editores, a no 38, n. 1935, p 58-65, maio 1989.

MANC HEIE ESPECIAL. Rio de Janeiro: Bloch Editores, ago. 1995. 
MEYER, Dag mar Estermann. "Gênero e educação: teoria e polític a". In: LOURO, G ua cira Lopes; NEC KEL, J a ne Felipe; GOELNER, Silvana V. Corpo, gênero e sexualidade: um debate contemporâneo na educação. Petrópolis: Vozes, 2003. p. 9-27.

MIC HELAT, Guy. "Sur I'utilisation de l'entretien non-direc tif en sociologie". Revue Française de Sociologie, XVI, p. 229-247, 1975.

MOSC OVICI, Serge. A representação social da psic a nálise. Rio de Janeiro: Zahar, 1978.

- Representações sociais: investigações em psicologia social. Petrópolis: Vozes, 2003.

MOURÃO, Ludmila. A representação social da mulher brasileira na a tividade físic o-desportiva: da segregação à democratização. 1998. Tese (Doutora do em Educação Física) - Programa de Pós-Graduação em Educação Física, Universida de Gama Filho, Rio de Ja neiro.

"Exclusão e inserção da mulher brasileira em atividades físic as e esportivas". In: SIMÕES, Antonio C. (Org.). Mulher e esporte: mito e verdades. São Paulo: Manole, 2003. p. 123-154.

MOURÃO, Ludmila; PEREIRA, Guilherme. "O cotidiano da Educação Físic a escola r". In: VOTRE, Sebastião; COSTA, Vera L. M (Orgs.). Cultura, a tividade corporal e esporte. Rio de J a neiro: EDUGF, 1995. p. 139-148.

MOURÃO, Ludmila; GOMES, Euza M. P. “Mulheres na administração esportiva brasileira: uma trajetória em curso". In: SIM ÕES, Antonio C.; KNIJ NIK, Jorge D. (Orgs.). O mundo psicossocial da mulher no esporte: comportamento, gênero, desempenho. São Paulo: Aleph, 2004. p. 278-335.

MOURÃO, Ludmila; GOMES, Euza M. P. “Women's Partic ipation in Sport Administration in South American Countries: A Place of Social Inclusion or Exclusion?" The FIEP Bulletin, v. 75, n. 1, p. 138-142, 2005.

MOURÃO, Ludmila; MOREL, Márcia "As narrativas sobre o futebol feminino: o discurso da mídia impressa em campo". Revista Brasileira de Ciências do Esporte, Campinas, v. 26, n. 2, p. 73-86, 2005.

OLVEIRA, Greice Kelly. Aulas de Educação Física para turma s mista s ou separa das por sexo. 1996. Disserta ção (Mestrado em Educação Física) - Programa de PósGradua ção em Educação Físic a, Universida de Esta dua I de Campinas, Campinas. 
PEREIRA, Sissi Aparecida Martins. O sexismo nas aulas de Educação Física: uma análise dos desenhos infantis e dos estereótipos de gênero nos jogos e brincadeiras. 2004. Tese (Doutora do em Educação Física ) - Programa de Pós-Graduação em Educação Física, Universidade Gama Filho, Rio de Janeiro.

REIS, Lucia M. Representações da mulher que joga futebol. 1997. Dissertação (Mestra do em Educação Física) Programa de Pós-Graduação em Educação Física, Universidade Gama Filho, Rio de Janeiro.

RELATÓRIO GERAL SOBRE A MULHER NA SOCIEDADE BRASILEIRA. IV Conferência Mundial sobre a Mulher. Beijing, China. Bra sília: Ed itora Fiocruz, 1995.

ROMERO, Ela ine. Estereótipos masculinos e femininos em professores de Educação Física. 1990. Tese (Doutora do em Psicologia) - Programa de Pós-Graduação em Psicologia, Universidade de São Paulo, São Paulo.

RORTY, Ric hard. Conting ência, ironia, solida rieda de. Lisboa: Presença, 1994.

SARAIVA, Maria do Carmo. Co-educa ção Físic a e esportes: quando a diferença é mito. ljuí: UNIJ Uí, 1999.

SART, Cyntia Andersen. "O feminismo brasileiro desde os anos 1970: revisitando uma trajetória". Revista Estudos Feministas, n. 12, v. 2, p. 35-50, 2004.

SCOT, Joan. "O enigma da igualdade". Revista Estudos Feministas, v. 13, n. 1, p. 11-30, jan./abr. 2005.

SIMÕES, Antonio C.; KNIJ NIK, Jorge D. (Orgs.). O mundo psicossocial da mulher no esporte: comportamento, gênero, desempenho. Sã o Paulo: Aleph, 2004.

SOIHET, Raquel. "História das mulheres". In: CARDOSO, C iro Flamarion; VAINFAS, Ronaldo (Orgs.). Domínios da História. Rio de Janeiro: Campus, 1997. p. 275-296.

SOUSA, Eustá quia Salvadora. Meninos à marcha! Meninas, à sombra! A história do ensino da Educação Física em Belo Horizonte (1987-1994). 1994. Tese (Doutora do em Educação ) - Programa de Pós-Graduação em Educação, Universidade Estadual de Campinas, Campinas.

SOUZA DE O LIVEIRA, Gabriela A. Representações socia is de mulheres técnicas sobre o comando de equipes esportivas de alto nível. 2003. Disserta ção (Mestra do em Educação Física) - Programa de Pós-Graduação em Educação Física, Universidade Gama Filho, Rio de Janeiro.

SOUZA DE OLIVEIRA, Gabriela A.; COSTA, Juliana Santos. "Atletismo feminino nos Jogos Olímpicos". In: DACOSTA, Lamartine P. (Org.). Atlas do esporte no Brasil. Rio de J aneiro: Shape, 2005. p. 250. 
STÖER, Stephen R.; MAGALHÃES, António M.; RODRIGUES, David. Lugares da exc lusão social. São Paulo: Contexto, 2003.

THIO LLENT, Michel. C rític a metodológica, investigação social e enquête operária. São Paulo: Polis, 1987.

TADEU DA SIVA, Tomaz; WOODWARD, Kathryin; HALL, Stuart. Identidade e diferença. Petrópolis: Vozes, 2005.

VERBENA, Eliete do Carmo Garcia. Esporte e gênero: representações entre estudantes da rede pública municipal de J uiz de Fora. 2001. Dissertação (Mestra do em Educação Física) - Programa de Pós-Graduação em Educação Física, Universidade Castelo Branco, Rio de J a neiro.

VOTRE, Seba stião; COSTA, Vera (Orgs.). Cultura, a tividade corporal e esporte. Rio de J a neiro: EDUGF, 1995.

VOTRE, Sebastião; FIGUEIREDO, Carlos. "Ancoragem e o bjetivação no ima ginário". In: VOTRE, Seba stião; MOURÃO, Ludmila et al. (Orgs.). Imaginário \& representações socia is em Educação Física, esporte e lazer. Rio de Janeiro: EDUGF, 2001. p. 269-280.

VOTRE, Sebastião; MOURÃO, Ludmila et al. (O rgs.). Imaginário \& representações socia is em Educação Física, esporte e lazer. Rio de J a neiro: EDUG F, 2001.

VOTRE, Seba stiã o; MOURÃO, Ludmila. "Ig noring Taboos: Maria Lenk, Latin American Inspirationalist". The International J ournal of the History of Sport, v. 18, n. 1, Freeing the Female Body, p.196-218, Mar. 2001.

VOTRE, Seba stião; MOURÃO, Ludmila. "Women's Football in Brazil: Progress and Problems". In: HONG, Fan, and MANGAN, J ohn. (eds.). Soccer, Women, Sexual Liberation - Kicking Off a New Era. London: Frank Cass Publishers, 2003. p. 254-267.

VOTRE, Seba stião. (Org.). Gramatic a liza ção. Rio de J a neiro: Editora da UFRJ, 2004.

WAGNER, Wolfgang. "Descrição, explicação e método na pesquisa das representações sociais". In: GUARESC HI, Pedrinho; J OVC HELOVITCH, Sandra (Orgs.). Texto s em representações sociais. Rio de J a neiro: Vozes, 2002. p. 149-186.

WELER, Wivian. "Gênero e juventude". Revista Estudos Feministas, v. 13, n. 1, p. 103-106, jan./abr. 2005.

WOODWARD, Kathryn. "Identidade e diferença: uma introdução teórica e conceitual". In: TADEU DA SIVA, Tomaz; WOODWARD, Kathryin; HALL, Stua rt. Identidade e diferença. Petrópolis: Vozes, 2005.

[Recebido em agosto de 2005 e aceito para publicação em maio de 2006] 
Academic and Sporting Insertion of the First Female Students in the Military College of Rio de Janeiro

Abstract: The goals of this article are to contextualize the ambiance in which the access of women in the Military College of Rio de Janeiro was observed, in 1989, and to identify and a nalyze masculine and feminine representations on the academic and sporting insertion of the first group of women in the school. The research was oriented by the approach of social representations, following Moscovici and Wagner. Data come from the analysis of magazines and newspapers related to the theme, from 1988 to 1996, and from six elite interviews held with three formal students and three teachers. It was concluded that the treatment offered to female students by teachers and colleagues was careful and protective. The support, guaranteed by the commander and a female teacher of physical education, influenced and consolidated the space for female participation and integration in the academic and sporting life of Military College.

Key Words: Women; Gender; Physic al Education; Social Representations; Military College. 